\title{
Design of Quadrotor UAV and Internet-of-Things Based Air Pollution Monitoring Systems
}

\author{
Adnan Rafi Al Tahtawi ${ }^{1}$, Erick Andika ${ }^{2}$, Maulana Yusuf ${ }^{3}$, Wildan Nurfauzan Harjanto ${ }^{4}$
}

\begin{abstract}
Air pollution is one of problems causing global warming that is currently taking a place. Several air quality monitoring devices usually located at the city center are only limited to display data at one point. Therefore, a mobile device to monitor air quality is needed so as to enable the monitoring in several points. This paper aims to design an air quality monitoring system based on quadrotor Unmanned Aerial Vehicle (UAV) and Internet-of-Things (IoT) technology. The sensor system is designed to detect $\mathrm{CO}, \mathrm{CO}_{2}$, air quality, and temperature variables. This sensor systems was then integrated with quadrotor in order to make the monitoring process can be carried out at various points. Quadrotor was designed using Ardupilot Mega (APM) 2.6 as the flight controler. Measurement data from system sensor was transmitted wirelessly using internet network via Wi-Fi module. Based on the test results, the sensor system was able to detect concentration of several test gas and was linear to the output voltage. Quadrotor orientation parameters at takeoff produced transient responses in less than 1 second. The air pollution sensor parameter data could also be displayed every 10 seconds on the ThingSpeak and ThingView interfaces, and could be mapped based on the data retrieval coordinates.
\end{abstract}

Keywords - Air pollution, Quadrotor, IoT, ThingSpeak.

\section{INTRODUCTION}

The growing world of industry and technology on this earth has an impact on environmental problems. One of the arising environmental problems is air pollution. The increasing number of motor vehicles,many industries that do not meet standards, and forest burning are some of causing factors of air pollution to occur. Based on the results of a research in an area, the use of motor vehicles had the largest percentage of other polluting gases, which ranged from $80.22 \%-90 \%$ [1] Possible solutions for this had also been offered, such as application of vehicle emission quality standards, restrictions on vehicle quantity, road environment management, and pollution-reducer-tree planting [2]. In order to facilitate an optimal realization of the pollution control solution, an integrated air pollution monitoring system is required. The existing pollution monitoring systems are usually located at

\footnotetext{
${ }^{1}$ Lecturer, Department of Electrical Engineering Bandung State Polytechnic, Jl. Gegerkalong Hilir, Ds. Ciwaruga, Bandung 40012 (Tel/fax: 022-2013789; e-mail: adnan.raf@polban.ac.id)

${ }^{2}$ Lecturer, Computer Engineering Study Program Sukabumi Polytechnic, Jl. Babakan Sirna No. 25 Sukabumi 41312 (Tel/fax: 0266-215417; e-mail: erickandika@polteksmi.ac.id)

${ }^{3,4}$ Alumni, Computer Engineering Study Program Sukabumi Polytechnic, Jl. Babakan Sirna No. 25 Sukabumi 41312 (Tel/fax: 0266-215417; e-mail: ukenmaulanayusuf@gmail.com; nurfauzan666@gmail.com)
}

one point and they are static. This can cause inaccuracies in the measurement data of air pollution parameters. Accordingly, a mobile monitoring system is required so as to enable air pollution monitoring in several points. One solution that can be carried out is to build an air pollution monitoring system by utilizing robotics and internet technology.

Unmanned Aerial Vehicle (UAV) and Internet-of-Things (IoT) technologies have developed and are widely used in recent years. UAV is a type of flying robot offering various benefits, such as mapping, disaster mitigation, monitoring from the air, up to photography. IoT-based technology has also been being developed because it facilitates humans doing various activities. Both of these technologies also provide more benefits if they are integrated stimultaneously. One example is the emergence of Internet-of-Drones (IoD) [3] concept with an application for logistics services [4]. Based on the background description, an integration of an air pollution sensor system, UAV, and IoT is a promising solution to overcome the aforementioned problems.

Several previous studies related to similar systems have been carried out in the last five years. In 2014, there were two studies designing an integrated UAV air pollution monitoring system. The first study designed a $\mathrm{CO}$ gas measuring instrument based on UAV. This system results showed that the system could work well and could measure $\mathrm{CO}$ gas with a range of 20-2,000 ppm [5]. The second study designed a system called Gas-Drone with the aim of mapping gas leaks in industrial areas by utilizing UAVs [6]. Furthermore, there were two similar studies conducted in 2015 . The first study designed a mobile pollution sensor system using a Raspberry Pi-based UAV by utilizing the GrovePi GPIO facility [7]. The second study designed a gas detection and monitoring system in the integrated UAV industry. This system was designed to detect $\mathrm{CO}$ levels using a gas sensor module transmitted to the ground segment using the ZigBee communication protocol [8]. There is one related study conducted in 2016, which was about mapping a pollutant gas distribution using UAV based on an Autonomous Waypoint Navigation method [9]. Then in 2017 there were two related studies conducted analytically and experimentally. The first study aimed to design a UAVbased air pollution monitoring system in a difficult-to-access area. The proposed system was a Pollution-driven UAV Control (PdUC) algorithm working based on the Particle Swarm Optimization (PSO) algorithm [10]. In the second study, the UAV system was used to monitor environmental conditions by using the ubidots.com web server [11]. Last but not least, the latest similar system had been designed in 2018 . The sensor system was developed using four sensor types, namely MQ-4 to detect Methane, MQ-7 to detect CO, MG811 to detect $\mathrm{CO}_{2}$, and MQ-135 to detect air quality. These four 


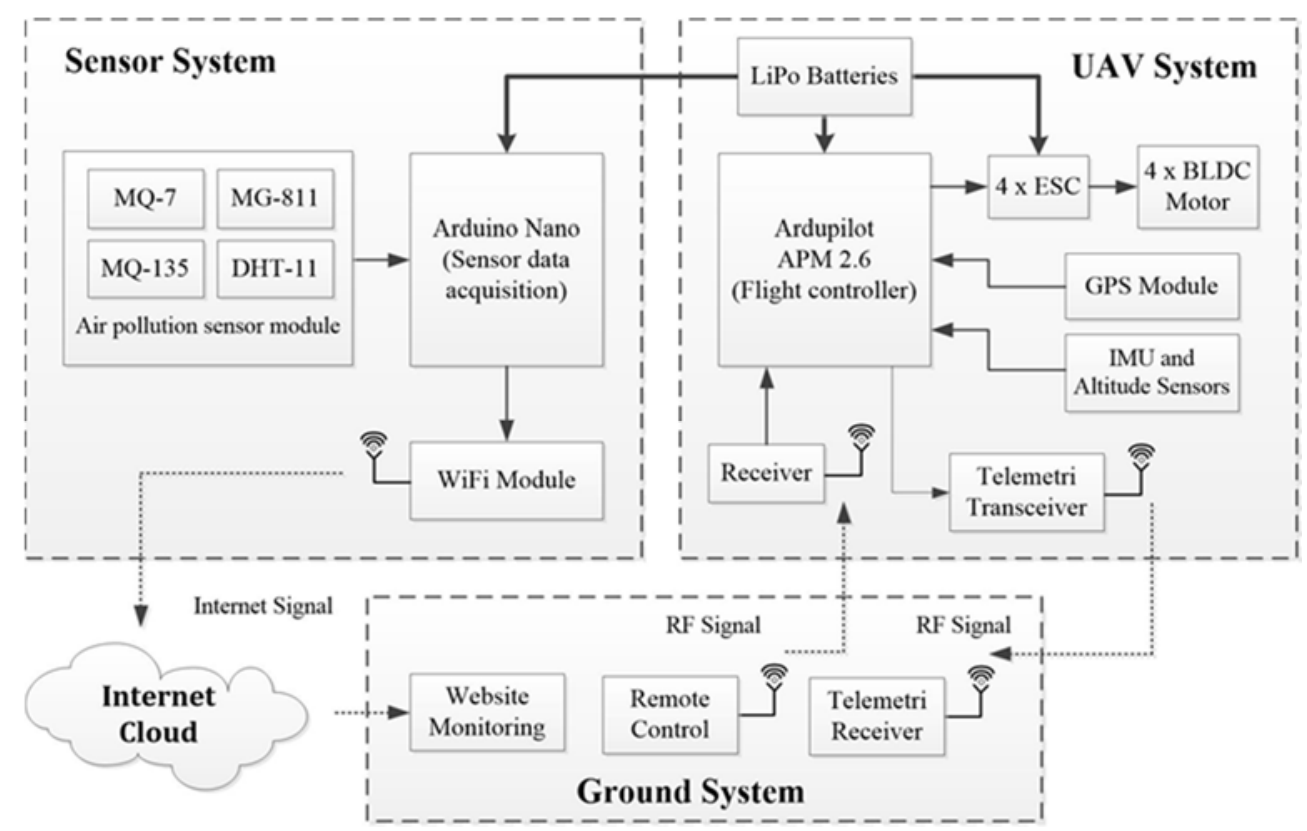

Fig. 1 System architecture.

sensors were connected to Arduino Mega 2560 microcontroller module and SD Card module. For monitoring requirement, the system was also equipped with a camera module and video transmitter. This system utilized Fault Tolerant Control (FTC) algorithm to eliminate disturbance and noise effects in sensor readings [12].

The purpose of this paper is to design an air quality monitoring system that can work mobile by utilizing quadrotor UAV and IoT technology. The sensor system is designed using several gas sensor modules and temperature sensors. This system is made in such a way that it can be integrated with a quadrotor system. In this paper, the quadrotor flying vehicle was self-designed with a low-cost concept using the APM 2.6 flight controller module as a flight control device. This module has been integrated with orientation and altitude sensors. In addition, this module can also be integrated with Global Positioning System (GPS) sensors so that the coordinates data of air pollution level at a point can be recognized. To facilitate access to monitoring, the IoT concept is also integrated by utilizing third-party applications, namely ThingSpeak and ThingView.

\section{SyStem DESIGN}

\section{A. System Architecture}

The system architecture design is divided into three parts, namely the sensor system design, UAV design, and the IoT design. Overall, a block diagram of administered system design is shown in Fig. 1.

In the sensor system section, there were five measured air parameters, namely MQ-7 to detect $\mathrm{CO}, \mathrm{MG}-811$ to detect $\mathrm{CO}_{2}, \mathrm{MQ}-135$ to detect air quality, and DHT-11 to detect air temperature. These four sensors were then connected to the Arduino Nano microcontroller module as a sensor data processing device. Then the sensor data was sent to the internet using a Wi-Fi module via a tethering connection. The sensor system obtained its power supply from a LithiumPolymer (LiPo) battery which was also a quadrotor power supply. In the UAV system, the quadrotor was designed using the APM 2.6 flight controller which had been integrated to orientation and position sensors. The IMU sensor consisting of a gyroscope and accelerometer as well as a GPS module was used as an orientation and position sensor for controling purposes. In the output section, there were four Electronic Speed Controller (ESC) and Brushless DC Motor (BLDC) units equipped with propellers as quadrotor drive systems. In the interface system on land, there were remote controls operated by pilots, telemetry data interfaces, and ThingSpeak and ThingView website interfaces. A telemetry data interface was used to display data of attitude, height and quadrotor position. The ThingSpeak and ThingView interfaces were used to display sensor reading data on desktop and smartphone devices.

\section{B. Air Quality Sensor System}

The sensor system was designed using four sensors to measure air condition parameters as explained earlier. The four sensors were then connected to a digital pin and Arduino Nano analogue input. The schematic details of this sensor system circuit are shown in Fig. 2 with the specifications of each sensor are presented in Table I.

Each sensor was given a power supply of $5 \mathrm{~V}$ obtained from the microcontroller voltage, except for the MG-811 sensor. This sensor was given a power supply of $6 \mathrm{~V}$ obtained from the buck converter output. This module served to reduce battery voltage so as to produce a voltage of $6 \mathrm{~V}$. The specifications of each sensor were obtained from the datasheet of each sensor. For straightforwardness, the collected data was only taken at working voltage and at the detection range of each measured scale. 


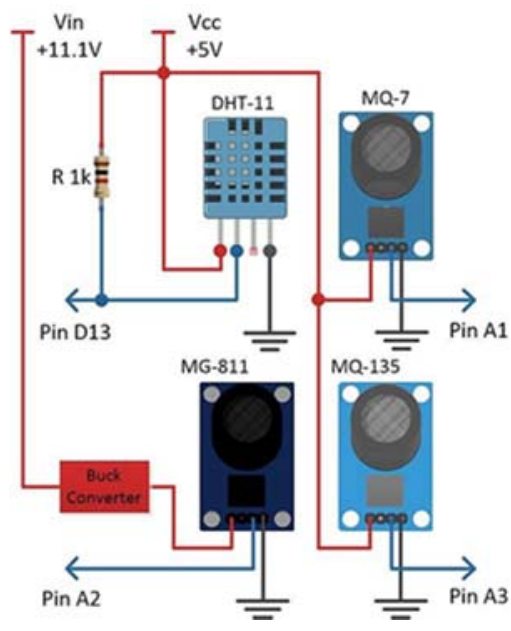

Fig. 2 Air pollution sensor system.

TABLE I

SPECIFICATIONS OF AIR QUALITY SENSOR SYSTEM

\begin{tabular}{|l|l|}
\hline \multicolumn{1}{|c|}{ Specification } & Description \\
\hline MQ-7 Sensor (CO) & $5 \mathrm{~V} \pm 0.1$ \\
\hline Working voltage & $-20^{\circ} \mathrm{C}-50^{\circ} \mathrm{C}$ \\
\hline Working Temperature & $20-2,000 \mathrm{ppm}$ \\
\hline Detection range & $6 \mathrm{~V} \pm 0.1$ \\
\hline MG-811 Sensor $\left(\mathbf{C O}_{2}\right)$ \\
\hline Working voltage & $-20^{\circ} \mathrm{C}-50^{\circ} \mathrm{C}$ \\
\hline Working Temperature & $350-10,000 \mathrm{ppm}$ \\
\hline Detection range & $5 \mathrm{~V}$ \\
\hline MQ-135 Sensor (Air Quality) \\
\hline Working voltage & $10-300 \mathrm{ppm}($ amonia), $10-$ \\
\hline Detection range & $1,000 \mathrm{ppm}(\mathrm{bensol})$, and 10 \\
\hline \multicolumn{2}{|c|}{$-300(\mathrm{alkohol})$} \\
\hline DHT11 Sensor (Temperature) \\
\hline Working voltage & $3.5 \mathrm{~V}-5 \mathrm{~V}$ \\
\hline Detection range & $0^{\circ} \mathrm{C}-50^{\circ} \mathrm{C} \pm 0.2$ \\
\hline
\end{tabular}

\section{Quadrotor UAV System}

Full specifications of the designed quadrotor are shown in Table II. In this paper, the utilized flight controller was APM 2.6 as shown in Fig. 3. This flight controller had been integrated with the IMU MPU-6050 orientation sensor module and altitude sensor. In addition, this module had integrated connections for GPS. This module also had an APM Planner interface that could be configured for data telemetry needs. For control needs, the device could also be set to control the flight attitude with the PID method as had been developed previously [13], [14]. The value of the control constants $K p$, $K i$, and $K d$ could be set with a trial and error method. In addition, quadrotor telemetry data could be directly observed at that interface.

\section{IoT System}

The IoT system aims to display measurement data of air pollution sensor through website and smartphone interfaces. There are several designs that can be designed by considering condition of the quadrotor-integrated sensor. The first design is to use a GSM module to transmit sensor measurement data

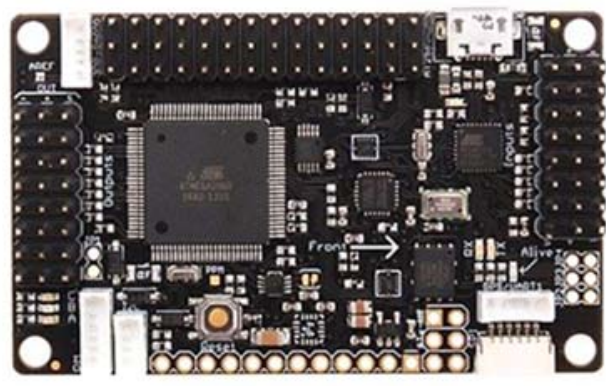

Fig. 3 APM 2.6 flight controller.

TABLE II

QUADROTOR SPECIFICATIONS

\begin{tabular}{|l|l|}
\hline \multicolumn{1}{|c|}{ Specification } & \multicolumn{1}{c|}{ Description } \\
\hline Microcontroller & Ardupilot Mega 2.6 \\
\hline Frame & F45 \\
\hline Sensor & $\begin{array}{l}\text { Gyroscope, Accelerometer, } \\
\text { Barometric Pressure, GPS }\end{array}$ \\
\hline Motor & 4 B BLC 1,000 kV \\
\hline ESC & 30 A \\
\hline Battery & Lithium Polymer 2,200 mAh \\
\hline
\end{tabular}

via SMS to the SMS server. The data is then forwarded to the database server which can then be accessed using the internet protocol. The second design is to use the GPRS module as a device that can function to transmit sensor data directly to the internet. Both of these designs have advantages because they use a GSM/GPRS connection that has a relatively wide range. However, these design also have weaknesses, namely the sensor data acquisition process requires several conversion stages, especially in the first design. The third design is to use a radio frequency module as a medium for transmitting sensor data from the air to the ground. Then the data received on land is transmitted to the database server via the internet network. The fourth design is to use a Wi-Fi module. Sensor measurement data is transmitted directly via $\mathrm{Wi}$-Fi connection obtained from land with a certain range. Both of these designs also have strengths and weaknessess. The third design's strength is the possibility of transmitting data from air to land in realtime, while the fourth design's strength is its simplicity in terms of configuration. The third design's weaknes is the need to create a receiver device stored on land, and the fourth design's weakness is the limited Wi-Fi network access range. Based on these design considerations, in this paper the fourth design was selected, as shown in Fig. 4.

Apart from having a simple configuration, by using a Wi-Fi network, measurement data can be directly transmitted to the website and smartphone interfaces. Even though it has a limited coverage, for the need to retreive pollution data it is considered sufficient and it does not require coverage from land to a remote quadrotor.

\section{RESULTS AND DISCUSSIONS}

\section{A. System Implementation}

After designing the system as a whole, the system was implemented, both in the form of hardware and IoT systems. 


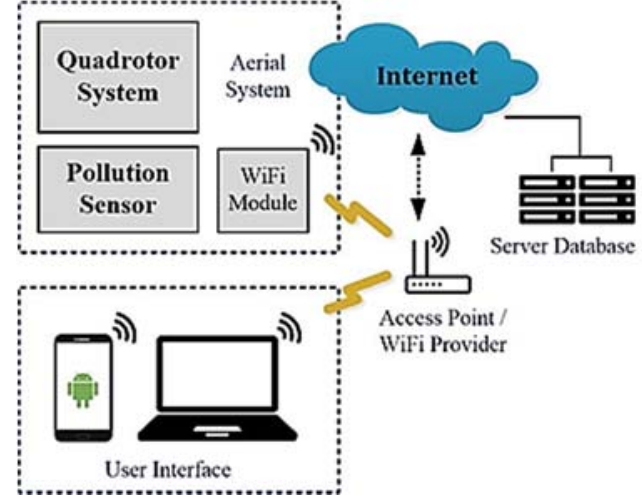

Fig. 4 IoT system design.

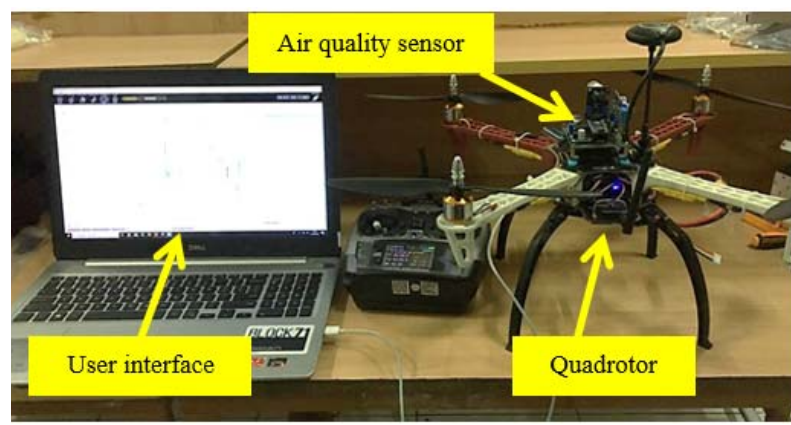

Fig. 5 Hardware implementation.

The results of the system implementation can be seen in Fig. 5 . The sensor system was placed at the top of the quadrotor, while the 2.6 APM and battery were placed at the center and bottom of the quadrotor. Sensor system placement at the top was carried out because there was no great air pressure at the top section as at the bottom of the quadrotor. In addition, gas sensor system placement at the top could also provide a better stability on the quadrotor flying attitude. Although a study of the effect of gas sensor placement on a quadrotor is required, the design of gas sensor system placement at the top can be considered the best. To find out the performance of each subsystem, a test was performed. In this paper, testing was carried out on sensor systems, quadrotor systems, IoT systems, and mapping.

\section{B. Sensor System Testing}

Sensor system testing aims to determine the data generated by the sensor in detecting air quality variables. Testing results of each sensor using several test scenarios are shown in Table III. Then, the correlation between the measured values in ppm units for each test scenario is shown in Fig. 6.

The test results show that the utilized gas sensor is able to detect the concentration of each different gas type. From the data obtained it appears that there is an increase in ppm value from normal air conditions when the sensor system is given a test scenario. The highest value is produced by the gas lighter test scenario by producing a $\mathrm{CO}$ value of $648 \mathrm{ppm}$. There is no significant changes in the resulted temperature. However, each test scenario type produces different temperatures. This is indicated by the difference in temperature sensor output voltage for each test scenario. The linearity between the

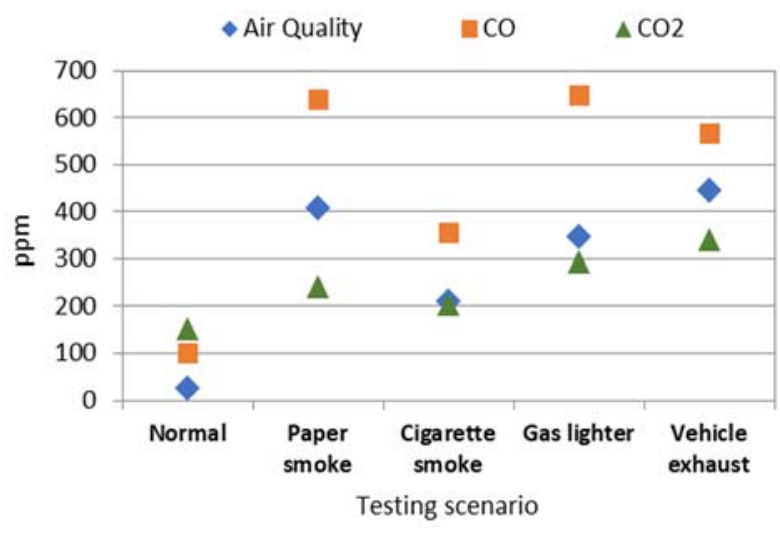

Fig. 6 Value of the gas concentration for each test scenario.
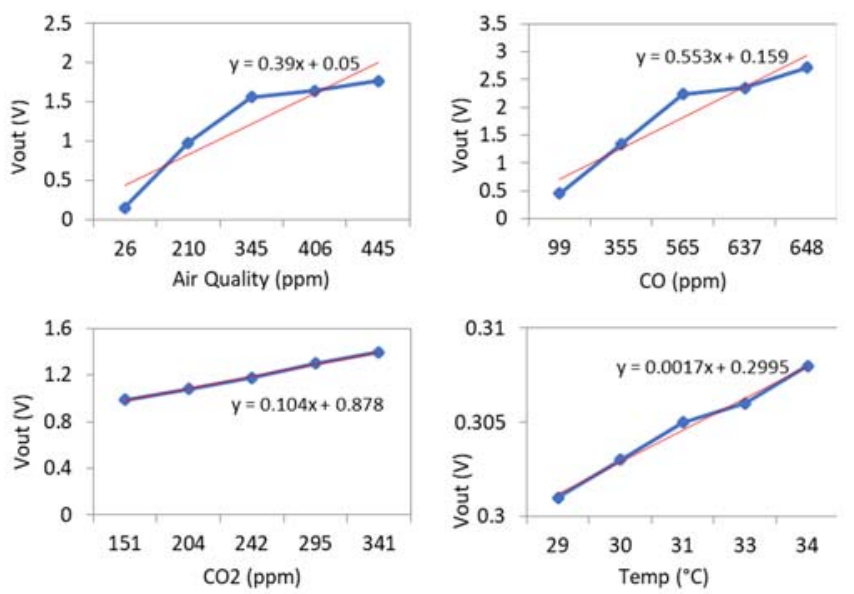

Fig. 7 Scale linearity measured with the output voltage.

TABLE III

Test Results of Gas And TEMPERATURE SENSOR MOdules

\begin{tabular}{|l|c|c|c|c|}
\hline \multirow{2}{*}{\multicolumn{1}{|c|}{ Scenario }} & \multicolumn{4}{c|}{ Output Voltage (V) } \\
\cline { 2 - 5 } & CO & $\mathbf{C O}_{2}$ & AQ & DHT11 \\
\hline Normal & 0.45 & 0.99 & 0.15 & 0.303 \\
\hline Paper smoke & 2.35 & 1.18 & 1.64 & 0.305 \\
\hline Cigarette smoke & 1.34 & 1.08 & 0.98 & 0.301 \\
\hline Lighter & 2.71 & 1.30 & 1.56 & 0.308 \\
\hline Motorcycle exhaust & 2.24 & 1.40 & 1.77 & 0.306 \\
\hline
\end{tabular}

output voltage and the measured scale for each sensor is shown in Fig. 7.

From this graph, it can be seen that scale value measured by the sensor has a linear relationship with the output voltage of each sensor. The most ideal linearity is produced by the MG-811 sensor, with the function $y=0.104 x+0.878$.

\section{Quadrotor System Testing}

The quadrotor system testing aims to find out the orientation and altitude sensor performance integrated in the flight controller APM 2.6. In addition, testing was also carried out on the GPS module used. Orientation sensor testing was carried out by moving the quadrotor in the six directions, namely the left roll, right roll, front pitch, back pitch, left yaw, and right yaw. After that, the results were observed in the APM Planner interface. This test was carried out to ensure the 


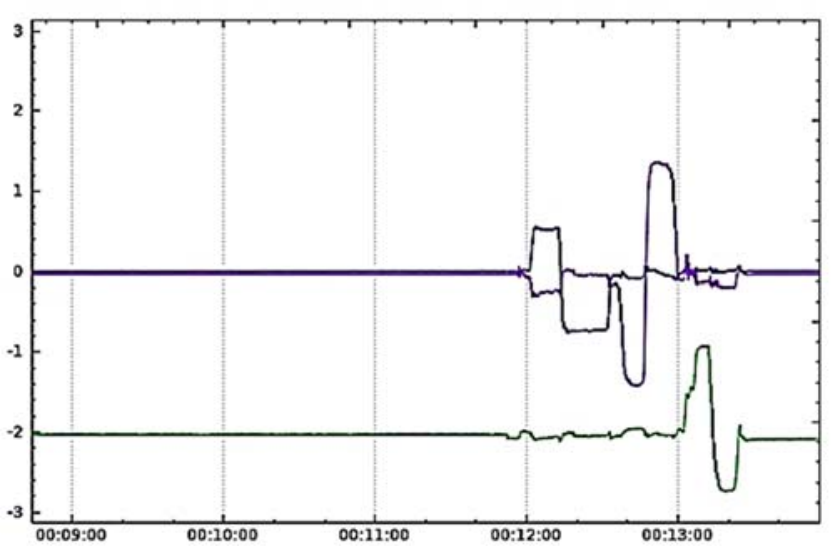

Fig. 8 Angular responses of roll (blue), pitch (purple), and yaw (green) vs. time.

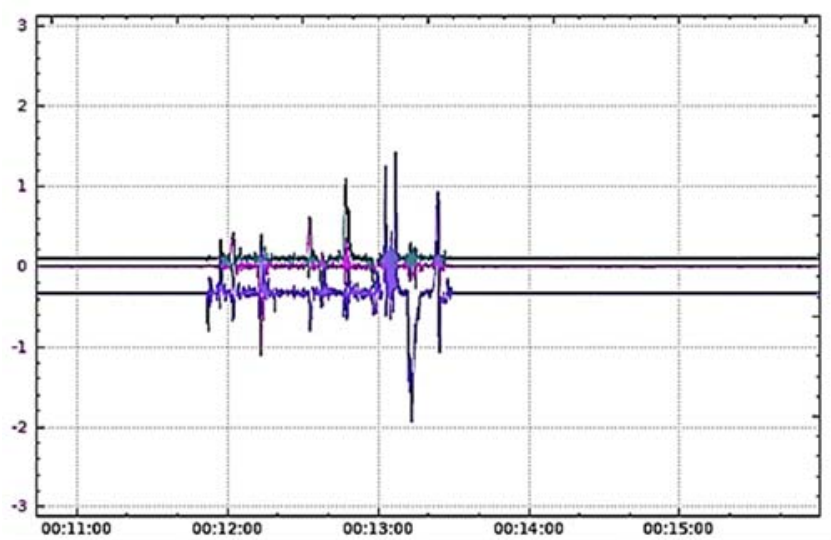

Fig. 9 Angular speed responses of roll (blue), pitch (purple), and yaw (green) vs. time.

quadrotor attitude was able to be controlled while in the air. The observed responses were the angle and angular velocity of the three quadrotor attitudes. The test results of the orientation sensor are shown in Fig. 8 and Fig. 9.

The test results show that the orientation sensor is properly able to detect the quadrotor attitude response even though there is still a measurement value offset. Angular responses in Fig. 8 show that all three attitudes are able to be detected according to the specified movements. At rest, the roll and pitch values are at angle of $0^{\circ}$, while the resulted yaw angle is at $-2^{\circ}$. Yaw angle offset value of $2^{\circ}$ is caused by a less precise sensors placement. The resulted angular velocity response in Fig. 9 shows that orientation sensor is able to detect angular velocity in accordance with motion specified to the quadrotor. From the test results there is an angular velocity offset value when the quadrotor is at rest, which is $-0.3 \mathrm{deg} / \mathrm{s}$ for the roll attitude and $0.1 \mathrm{deg} / \mathrm{s}$ for the yaw attitude. To minimize the offset values presence in each data, a re-calibration is required on the flight controller module placement.

After that, the quadrotor flying attitude was tested when taking-off. Tests were carried out to ensure the quadrotor can fly stably to carry out its mission. When taking-off, the three quadrotor attitude data were observed through the APM planner interface. The test result of the three quadrotor flying attitudes during take-off are shown in Fig. 10.

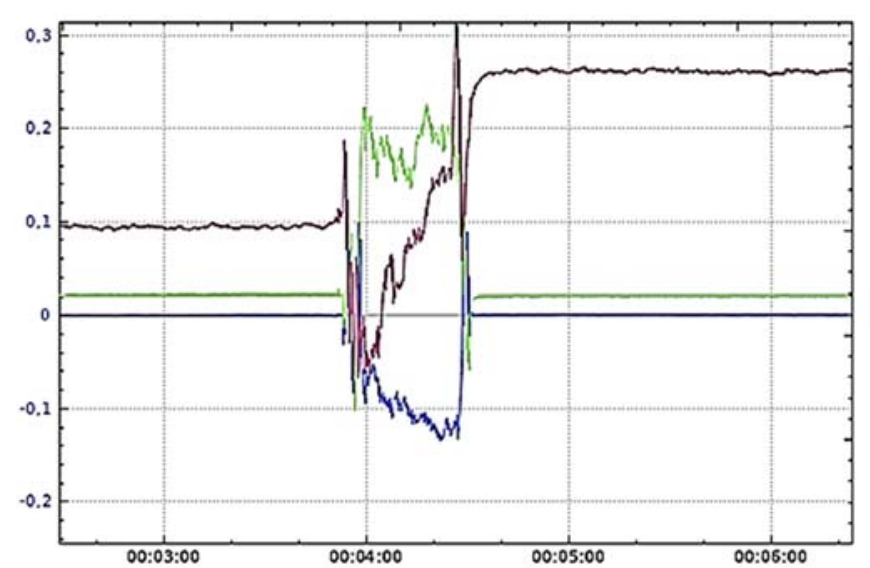

Fig. 10 Angular responses of roll (blue), pitch (green), and yaw (purple) vs. time when taking off.

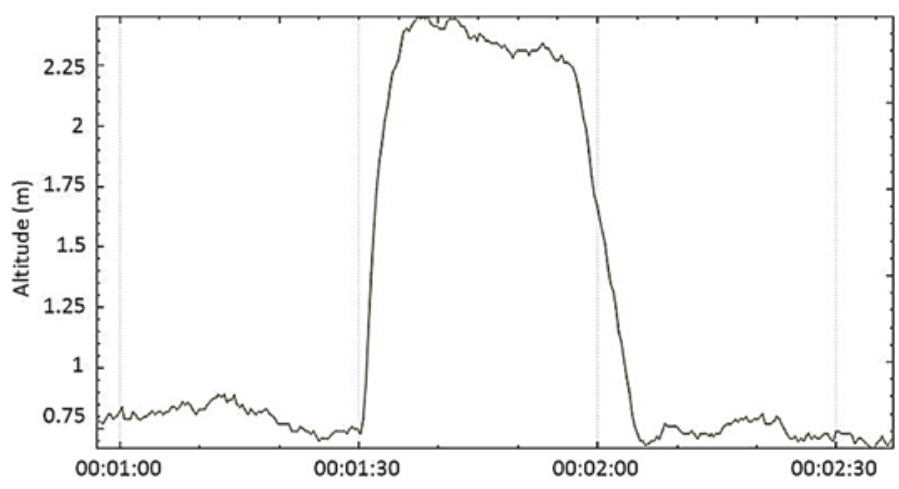

Fig. 11 Quadrotor altitude test when flying and landing.

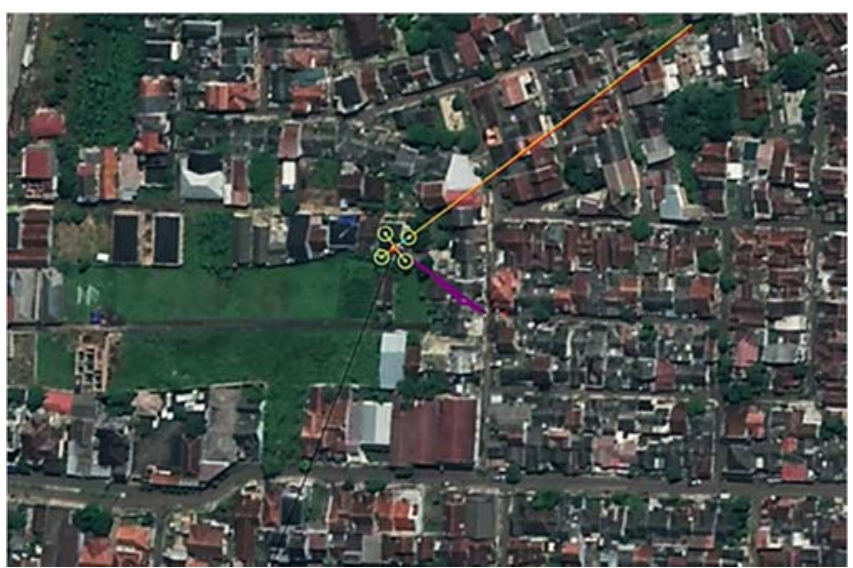

Fig. 12 Quadrotor coordinates display when flying.

Based on the test results, it is recognized that the quadrotor can take off well, although there is a transient response of about 0.5 seconds. In addition to observing the flying attitude, the altitude and coordinate data from the quadrotor can also be observed at the interface. The results of altitude and coordinate measurements obtained during quadrotor take-off, moving, and landing are shown in Fig. 11 and Fig. 12.

The test results show that the altitude value and coordinates can be detected by the altitude sensor and GPS contained in the quadrotor. Therefore, overal quadrotor systems can work well. 


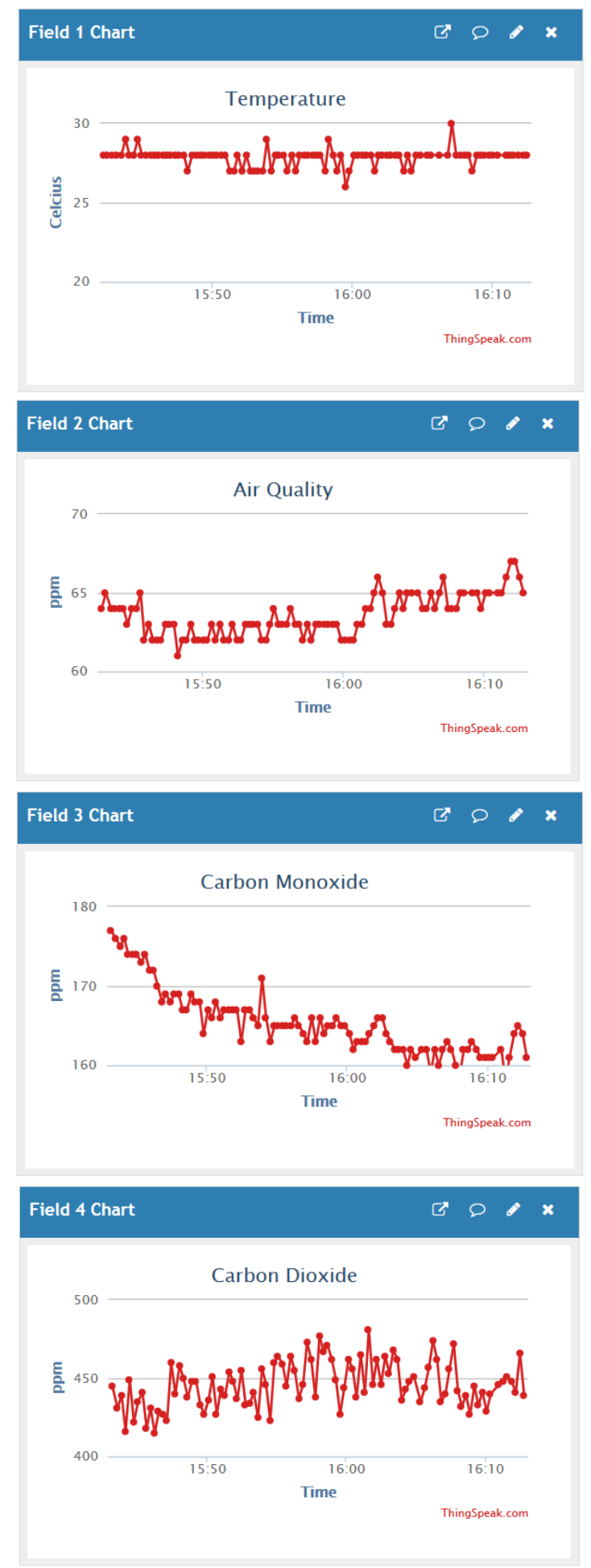

Fig. 13 Display of ThingSpeak website interface.

\section{IoT System Test}

IoT system test was carried out with the aim of knowing the data transmission process from the sensor system flown by a quadrotor to the ThingSpeak website interface and the ThingView Android application. On the ThingSpeak interface device an account was first created so that the user could design the interface system. After entering the system, then

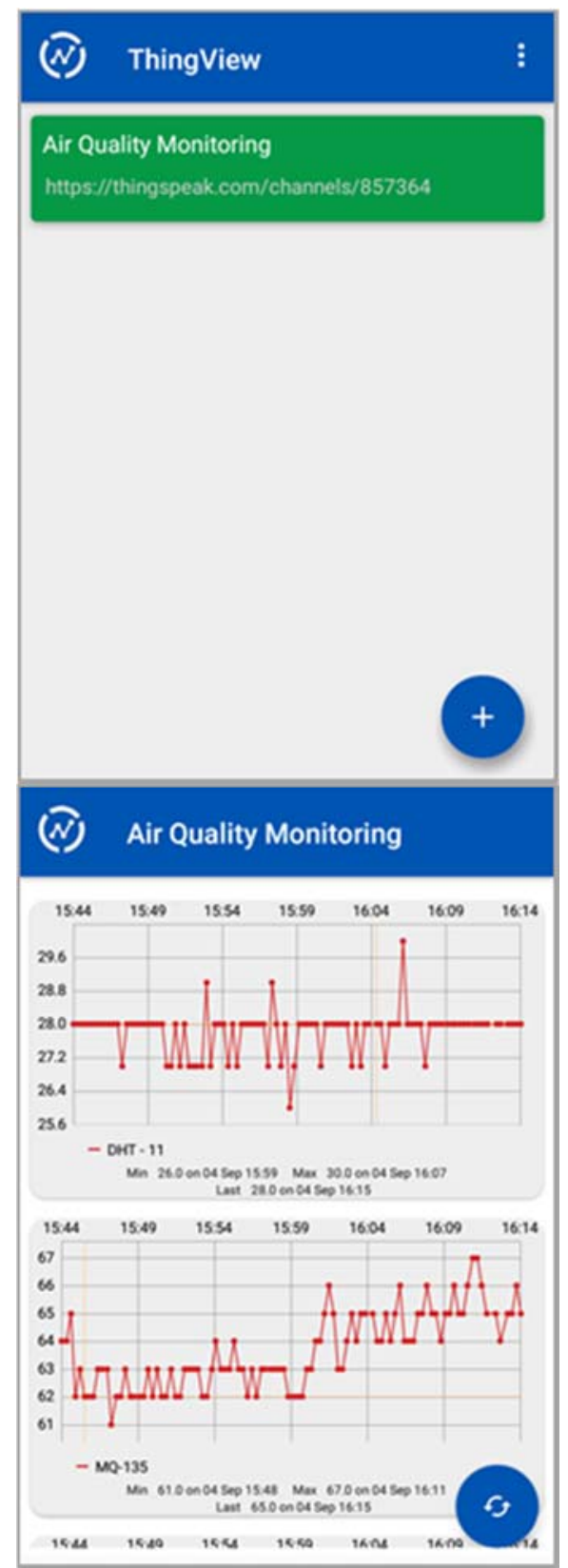

Fig. 14 Display of Android-based interface using ThingView.

the user created channels and fields as needed. In this paper, a channel that is publicly accessible is used. The interface was designed using four fields displaying temperature, air quality, $\mathrm{CO}$, and $\mathrm{CO}_{2}$ data. Data transmission time from sensor devices to interface systems was set for once every 10 seconds, in IDE Arduino programming. The system interface test results on the ThingSpeak website are shown in Fig. 13, while the display on the Android ThingView interface is displayed in Fig. 14.

From the test results, it appears that measurement data from the air pollution sensor system can be displayed on the ThingSpeak and ThingView interfaces. Both of these interface systems can be accessed publicly at the address https://thingspeak.com/channels/857364. Users can manage these data such as exporting to Ms. files. Excel and doing 


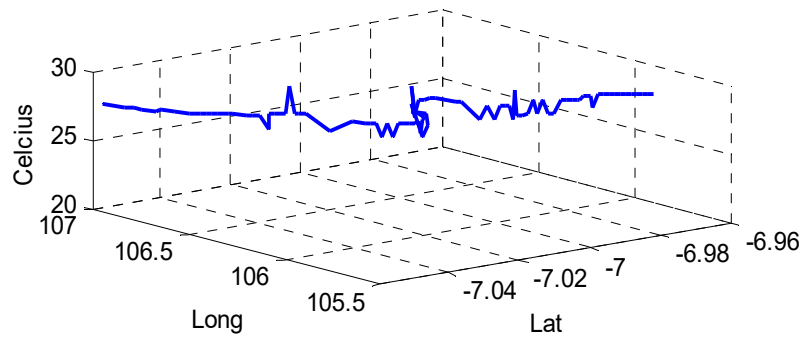

Fig. 15 Test of emperature parameters to coordinates.

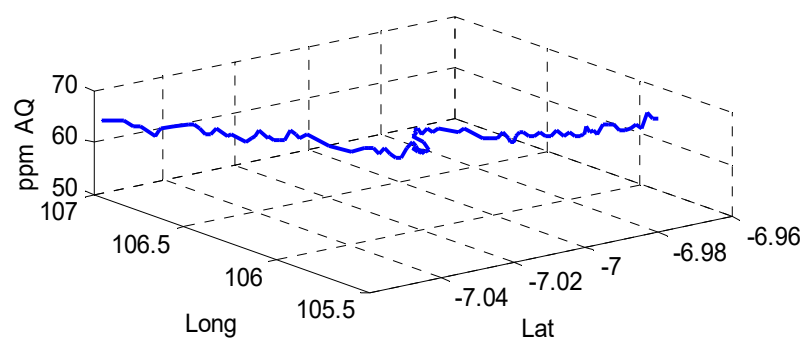

Fig. 16. Test of air quality parameters to coordinates.

analysis with MATLAB, while the observers can not download data or export to file form. This measurement data was obtained from a sensor system flown by a quadrotor via a Wi-Fi tethering network.

\section{E. Air Pollution Parameters Mapping}

The last test was performed to display the parameters of air pollution based on quadrotor coordinate data. Pollution data was taken manually using a pilot from one point to another. The data was then exported into Ms. format. Excel available on the ThingSpeak interface. After that, the pollution data was mapped according to the quadrotor coordinates obtained from the APM Planner interface using MATLAB software. The results of temperature, air quality, $\mathrm{CO}$, and $\mathrm{CO}_{2}$ mapping are shown respectively in Fig. 15 to Fig. 18.

According to the test results, it can be recognized that air pollution parameters can be measured and mapped based on the coordinates as has been done in [12]. However, the research did not apply the concept of IoT, therefore measurement data cannot be accessed publicly. The obtained measurement data can also be influenced by quadrotor flying attitude. The more stable the flight attitude, the obtained air pollution data is more accurate. This can be overcome by optimizing the PID controller found in APM 2.6. flight controller. When correlated with the IoT system, the measured pollution data is also affected by the connectivity of the ESP8266 Wi-Fi module found in the gas sensor system. The flight attitude stability can affect the internet network stability and the pollution data accuracy. Therefore, quadrotor flying attitude stability is the main key so that internet network connectivity can work stably and the pollution measurement data is more accurate. Further development can be carried out by conducting mapping in several areas prone to air pollution, such as industrial and urban areas. The method that can be used is the Waypoint Navigation System (WNS) as in [9] by integrating the IoT concept in it.

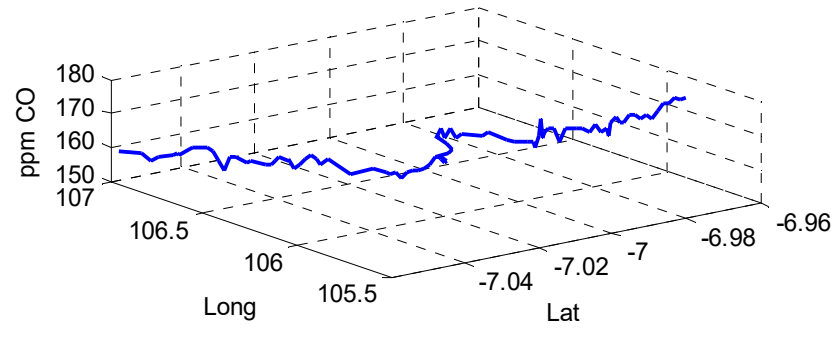

Fig. 17 Test of CO parameters to coordinates.

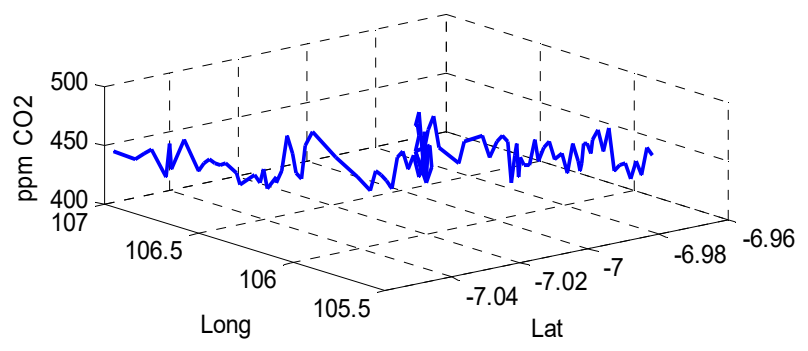

Fig. 18 Test of CO parameters to coordinates.

\section{CONCLUSION}

The quadrotor and IoT technologies integrated air quality monitoring system had been successfully designed and implemented. Air pollution parameters could be measured using a sensor system flown along with a quadrotor. Based on the test results of several subsystems, it was found that the system could work well. The sensor system that could detect the scales of temperature, air quality, $\mathrm{CO}$, and $\mathrm{CO}_{2}$ was the MG-811 sensor, the $\mathrm{CO}_{2}$ detectors, with a linearity that almost close to ideal. The highest ppm value was obtained in $\mathrm{CO}$ gas testing, which was equal to $648 \mathrm{ppm}$. The results of the quadrotor subsystem testing also gave good results, namely the orientation sensor was able to detect angles and angular velocity even though there was still an offset value, with the largest value of $2^{\circ}$, namely on the yaw attitude. The transmission of air pollution sensor data to the ThingSpeak and ThingView interfaces had also been successfully carried out with a transmission time every 10 seconds. In conclusion, air pollution measurement data had also been mapped according to coordinates obtained from the APM Planner interface. Accordingly, the air pollution parameters could be monitored mobile at several points. The next research is mapping air pollution based on several points autonomously using the waypoint method, and integrating the coordinate system on the IoT interface device.

\section{ACKNOWLEDGEMENTS}

Our gratitude is presented to the Directorate of Research and Community Service (DRPM) of the Ministry of Research and Technology for funding support for this research through the Beginner Lecturer Research Grant with Contract Number: 2787//L4//PP/2019.

\section{REFERENCES}

[1] S.L. Sengkey, F. Jansen, and S. Wallah, "Tingkat Pencemaran Udara CO Akibat Lalu Lintas dengan Model Prediksi Polusi Udara Skala 
Mikro," Jurnal Ilmiah Media Engineering, Vol. 1, No. 2, pp. 119-126, 2011.

[2] N. Kusminingrum and G. Gunawan, "Polusi Udara Akibat Aktivitas Kendaraan Bermotor di Jalan Perkotaan Pulau Jawa dan Bali," Jurnal Puslitbang Jalan dan Jembatan Jakarta, Vol. 25, No. 3, pp. 1-13, 2008.

[3] M. Gharibi, R. Boutaba, and S.L. Waslander, "Internet of Drones," IEEE Access, Vol. 4, pp. 1148-1162, 2016.

[4] G.S.D. Kumar and A.J. Rajasekhar, "Drone Based Service System Using Internet of Things (IoT) Technology," International Journal of Scientific Research in Science, Engineering and Technology (IJSRSET), Vol. 4, No. 4, pp. 429-435, 2018.

[5] A.N. Hidayah, D. Triyanto, and Y. Brianorman, "Perancangan Alat Ukur Gas Karbon Monoksida (CO) Berbasis Pesawat Tanpa Awak," Coding Jurnal Komputer dan Aplikasi, Vol. 2, No. 1, pp. 26-33, 2014.

[6] M. Rossi, D. Brunelli, A. Adami, L. Lorenzelli, F. Menna, and F. Remondino, "Gas-Drone: Portable Gas Sensing System on UAVs for Gas Leakage Localization," Proc. IEEE SENSORS, 2014, pp. 1-4.

[7] O. Alvear, C.T. Calafate, E. Hernández, J.C. Cano, and P. Manzoni, "Mobile Pollution Data Sensing Using UAVs," Proc. International Conference on Advances in Mobile Computing and Multimedia (MoMM), 2015, pp. 393-397.

[8] A.C. Peng and C.Y. Hsu, "Integration of an Unmanned Vehicle and Its Application to Real-time Gas Detection and Monitoring," Proc. IEEE
International Conference on Consumer Electronics-Taiwan (ICCE-TW), 2015, pp. 320-321.

[9] B.F. Priyanta, M. Rivai, and R. Dikairono, "Pemetaan Distribusi Gas Polutan Menggunakan Quadcopter Berbasis Autonomous Waypoint Navigation,” Jurnal Teknik ITS, Vol. 5, No. 2, pp. 154-159, 2016.

[10] O. Alvear, N.R. Zema, E. Natalizio, and C.T. Calafate, "Using UAVbased Systems to Monitor Air Pollution in Areas with Poor Accessibility," Journal of Advanced Transportation, Vol. 2017, pp. 1-14, 2017.

[11] N. Ya'acob, M. Zolkapli, J. Johari, A.L. Yusof, S.S. Sarnin, and A. Zaied, "UAV Environment Monitoring System," Proc. International Conference on Electrical, Electronics and System Engineering (ICEESE), 2017, pp. 105-109.

[12] H. Mazeh, M. Saied, and C. Francis, "Development of a Multirotorbased System for Air Quality Monitoring," Proc. Third International Conference on Electrical and Biomedical Engineering, Clean Energy and Green Computing (EBECEGC), 2018, pp. 23-28.

[13] A.R. Al Tahtawi and M. Yusuf, "Implementasi Sistem Kendali Lepas Landas Quadrotor Menggunakan Pengendali PID," Prosiding Seminar Nasional Energi dan Teknologi (SINERGI), 2017, pp. 160-170.

[14] A.R. Al Tahtawi and M. Yusuf, "Low-cost Quadrotor Hardware Design with PID Control System as Flight Controller," TELKOMNIKA, Vol. 17, No. 4, pp. 1923-1930, 2019. 